Aslı Haykır Solay (D)

Hanife Uzar (1)

Ali Acar (1)

Fatma Eser (1)

Aşısına Yaklaşımı, Aşılanma Oranları ve Nozokomiyal İnfluenza Sıklığı

Zehra Gül Duman (1)

İrfan Şencan (D)

Deniz Yüce (1)

\title{
Health Workers' Attitudes Toward Influenza \\ Vaccine, Vaccination Rates, and Incidence of \\ Nosocomial Influenza in a Tertiary Care Center
}

öz

Sağlık personelinin influenza aşııı ile aşılanması ile kişsinin hastalanması ve iş gücü kaybı önlenebilir. Aynı zamanda personelin bakım verdiği hastalara bulaş da önleneceği için nozokomiyal influenza (Ni) sıklığını da etkiler. Çalışmamızda hastanemizdeki sağılk personelinin influenza aşısına karşı tutumları ve aynı dönemde hastanemizde görülen Ni olgularının irdelenmesi amaçlanmıştır.

7-17 Ocak 2019 tarihlerinde hastanemiz sağlık çalışanları ile yüz yüze görüşülerek anket formu doldurulmustur. Aynı zamanda 01 Ekim 2018- 01 Haziran 2019 tarihleri arasında hastanemizde yatan ve influenza benzeri hastalık bulguları olan hastaların dosyaları incelenerek Ni olguları irdelenmiştir. Anket, hasta bakımında aktif olarak çalışan 637 sağılı personeline uygulanmıştır. Katılımcıların \% 62 (n=393)'si kadın olup yas ortalamaları 35,32 $( \pm 9,8)$ yıl olduğu görülmüstür. 2018-2019 influenza sezonunda aşı olan $66(\%$ 10,4) kişi bulunmaktadır. Doktorların \% 13,8 (33/240)'lik aşılanma oranı ile uyumu en yüksek grup olduğu görülmüştür. Aşılanmamanın en sık nedeninin aşının koruduğuna inanmama $(\%$ 28,6) olduğu görülmektedir. 2018-2019 influenza sezonunda hastanemizde yatan ve influenza benzeri hastalık tanısı ile nazofaringeal sürüntü alınan 59 hastanın dosyası incelenmiștir. Bunlardan 19'u $(\%$ 32,2) ise Ni olarak değerlendirilmiştir. Dokuzunda pnömoni gelişsmiştir. Ü̧̧ hasta $(\% 15,7)$ influenza pnömonisi sonrası kaybedilmiștir. On dokuz hastanın yalnızca üçünde etken PCR ile izole edilmiştir. (H3N2; $n=2, H 1 N 1 ; n=1)$. Vefat eden üç hastanın birinde etkenin H3N2 olduğu görülmüştür.

Sağılı çalısanları tarafından influenza hastalığı, bulaștıııılığı önemsenmemekte ve assıya güvenilmemektedir. Farkındalı̆ı arttırmak için etkin eğitim yöntemleri kullanılmalıdır. istenilen așılama oranlarına ulaşılamadığında ise sağlık çalışanlarının zorunlu aşılanması konusunda değerlendirmeler yapılmalıdır.

Anahtar kelimeler: aşı, influenza, nozokomiyal, sağılı çalışanı

ABSTRACT

Influenza vaccination of health care personnel can prevent illness and loss of labour. It also prevents the transmission from personnel to patients, thus lowering the incidence of nosocomial influenza (NI). In this study, we examined the attitudes of health care personnel in our hospital toward the influenza vaccine and investigated cases of NI documented in our hospital during the same period.

A questionnaire was completed via face-to-face interviews with health workers in our hospital between January 7-17, 2019. The records of patients who were admitted to our hospital and had signs of the influenza-like disease between October 1, 2018, and June 1, 2019, were reviewed, and cases of NI were analysed.

The questionnaire was administered to 637 health workers actively working in patient care. Sixty-two percent $(n=393)$ of the participants were female, and the mean age was $35.32( \pm 9.8)$ years. Of the 637 respondents, $66(10,4 \%)$ were vaccinated in the 2018-2019 influenza season. Doctors showed the highest vaccination rate, with $13.8 \%(33 / 240)$. The most common reason cited for not getting vaccinated was not believing that the vaccine was protective $(28,6 \%)$. We examined the files of 59 patients who were admitted to our hospital during the 2018-2019 influenza season and from whom nasopharyngeal swabs were obtained due to a diagnosis of influenza-like disease. Of these, 19 (32,2\%) were NI. Nine of those patients developed pneumonia, and three patients $(15,7 \%)$ died as a result of influenza-pneumonia. A causative agent could be isolated by PCR in only three patients of the 19 patients (H3N2 in 2 patients, H1N1 in 1 patient). H3N2 was identified as the causative agent in 1 of the three patients who died.

Health workers do not give importance to the contagiousness of influenza and do not trust the vaccine. Effective training methods should be used to raise awareness. If desired vaccination rates are not reached, the possibility of mandatory influenza vaccination for health care personnel should be investigated.

Keywords: health-care professional, influenza, nosocomial, vaccine

(C) Telif hakkı Antibiyotik ve Kemoterapi (ANKEM) Derneği'ne aittir. Logos Tıp Yayıncilık tarafindan yayınlanmaktadır. Bu dergide yayınlanan bütün makaleler Creative Commons Atff-Gayri Ticari 4.0 Uluslararası Lisansı ile lisanslanmıştı.

(C) Copyright Society of Antimicrobial Chemotherapy. This journal published by Logos Medical Publishing.

Licenced by Creative Commons Attribution-NonCommercial 4.0 International (CC BY-NC 4.0)
Gelis/Received: 17 Ekim/September 2019

Kabul/Accepted: 03 Şubat/February 2019

Basım/Published: 30 Nisan/April 2020

Atıf/Cite as: Haykır Solay A, Uzar H, Acar A, Eser F, Gül Z, Şencan I ve ark. Üçüncü basamak sağlık hizmeti veren bir merkezde sağıı çalışmalarının influenza aşısına yaklaşımı, aşılanma oranları ve nozokomiyal influenza sıklı̆ı. ANKEM Derg. 2020;34(1):6-12.

Aslı Haykır Solay

Dışkapı Yıdırım Beyazıt EAH Enfeksiyon Hastalıkları ve Klinik Mikrobiyoloji Kliniği Ankara - Türkiye aahaykir@hotmail.com ORCID: 0000-0002-1326-9776

H. Uzar 0000-0003-4358-5777

A. Acar 0000-0003-2008-5112

F. Eser 0000-0002-0282-6346

Z. Gül Duman 0000-0002-3762-4533

i. Şencan 0000-0003-0465-5090

D. Yüce 0000-0003-0725-5447 Dışkapı Yıdırım Beyazıt EAH Enfeksiyon Hastalıkları ve Klinik Mikrobiyoloji Kliniği Ankara - Türkiye 
A. Haykır Solay ve ark., Üçüncü Basamak Sağlık Hizmeti Veren Bir Merkezde Sağlık Çalışanlarının İnfluenza Aşısına Yaklaşımı, Aşılama Oranları ve Nozokomiyal İnfluenza Sıklığı

\section{GiRiş}

Influenza virüsü her yıl salgınlara neden olmaktadır. Hastane kaynaklı olanlar tüm olguların \% 20'sini oluşturmaktadır ${ }^{(21)}$. Sağlık çalışanları klinik belirtileri olmadan da virüsü taşıyarak hastalara bulaştırabilmektedir ${ }^{(22)}$. Virüs ile karşılaşan bireylerin çoğu sekelsiz iyileşmektedir. Fakat yaşlılar, küçük çocuklar, gebeler ve kronik hastalığı olanlarda şiddetli hastalığa, hatta ölümlere neden olabilmektedir. Risk altında olan bu bireylerin influenzadan korunması için en etkili yol her yıl aşılanmalarıdır. Sağlık çalışanlarının aşılanması ile, çalışanın kendi sağlığını korumasının yanı sıra sağlık hizmeti verilen hastalara bulaş da engellemektedir(10). Ancak sağlık çalışanlarının aşıya uyumunun oldukça düşük olduğuna dair veriler mevcuttur. Bununla ilişkili olarak çalışanlarda asemptomatik taşıyıcılık ve influenza virus enfeksiyonu sıklığında artış, sonrasında hastanede yatan hastalarda nozokomiyal influenza (Ni) görülmektedir. Ni salgınları özellikle komorbiditesi olan hastalar olduğu için ağır klinik tablo ile ilişkilendirilmektedir ${ }^{(12)}$. Bu çalışma hastanemizde yatan hastalarda gelişen Ni olgularını değerlendirmek, aynı zaman dilimi içerisinde sağlık çalışanlarındaki aşılanma oranı ve aşı ret nedenlerini tespit etmek amacıyla planlanmıştır. Aşılanmama nedenlerinin ortaya konularak buna yönelik geliştirilecek stratejilerle aşılanma oranının artırılmasına yönelik politikaların belirlenmesine katkı sağlayacağını düşünmekteyiz. Ayrıca Ni olgularının değerlendirilmesi, sağlık çalışanlarının neden aşılanması gerekliliğini yeniden vurgulayacaktır.

\section{GEREÇ VE YÖNTEM}

Bu çalışma, 7-17 Ocak 2019 tarihlerinde bir eğitim araştırma hastanesinde yapılan tanımlayıcı tipte bir çalışmadır. Sağlık çalışanları ile yüz yüze görüşülerek anket formu doldurulmuştur. Bu ankette çalışanın yaşı, cinsiyeti, mesleği, kronik hastalık varlığı, grip olduğunda bakım verdiği hastalara bulaşacağını bilip bilmediği, daha önceki sezonlarda ve son influenza sezonunda aşı olup olmadığı, aşı olmadıysa nedeni sorulmuştur. Ankete katılan çalışanların demografik özellikleri ile aşılanma oranları arasındaki ilişki, aşı olmayanların aşı ret nedenleri irdelenmiştir. Hayatı boyunca hiç influenza aşısı olmamış olanlar grup 1, daha önceki sezonlarda aşı olduğu halde 2018-19 sezonunda aşılanmayı reddedenler grup 2 olarak tanımlanmıştır. Katılımcılardan, kendisinin aşıyı reddetmesine neden olan her sebebi işaretlemesi istenmiştir.

01 Ekim 2018-01 Haziran 2019 tarihleri arasında hastanemizde yatan ve influenza benzeri hastalık bulguları olması nedeniyle orofaringeal ya da nazofaringeal sürüntü örneği alınan hastaların dosyası incelenmiştir. Örnekler Transystem Steril Transport Swab ile alınarak Türkiye Halk Sağlığı Kurumu Referans Laboratuvarına iletilmiş; burada polimeraz zincir reaksiyonu (PCR) yöntemi ile influenza virüsü aranmıştır. Hastaneye yatışından 72 saat ve sonrasında gelişen influenza benzeri hastalık bulguları olan hastalar Ni olarak değerlendirilmiştir. Bu tanıma uyan hastaların yaşı, cinsiyeti, mevcut olan kronik hastalığı, pnömoni varlığı, orofaringeal ya da nazofaringeal sürüntü örneği sonucu ve tedavi yanıtı kaydedilmiştir.

Verilerin istatistiksel analizleri SPSS 15 (SPSS Inc., Chicago, IL, ABD) programı kullanılarak yapılmıştır. Verilerin analizinde Pearson X2 korelasyon ve Fisher'in kesin testleri kullanılmıştır. İkiden fazla grupların ortalamaları arasındaki fark ANNOVA ile değerlendirilmiştir.

Çalışmanın yapılması için yerel etik kuruldan onay alınmıştır.

\section{BULGULAR}

Hastanemizde, hasta bakımında çalışan 2044 kişiden 637'sine ulaşııp sözlü onay alınarak çalışmaya dahil edilmiştir. Katılımcıların \% 62 (n=393)'si kadın olup yaş ortalamaları $35,32( \pm 9,8)$ yıl olduğu 
- Yaş grupları

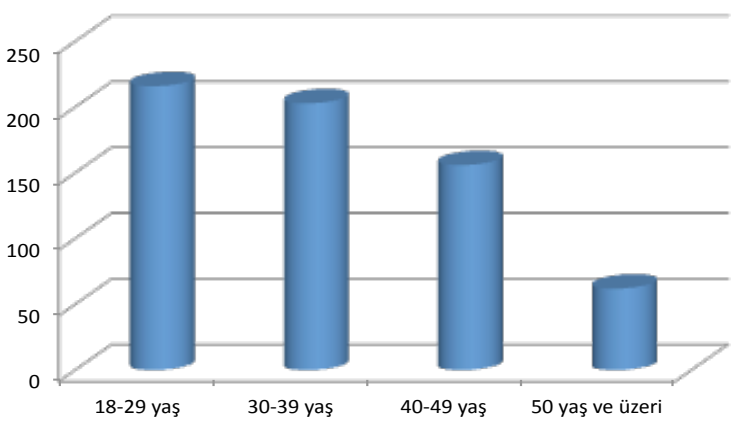

Şekil 1. Çalışmaya katılan sağlık çalışanlarının yaş gruplarına göre dağılımı.

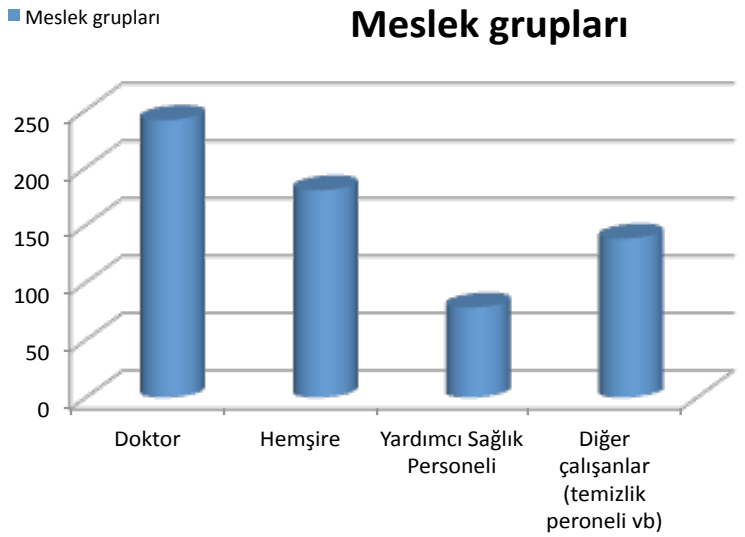

Şekil 2. Çalışmaya katılan sağlık çalışanlarının meslek gruplarına göre dağılımı.

Tablo 1. Ankete katılan çalışanların demografik özelikleri ve aşılanma oranları.

\begin{tabular}{|c|c|c|c|c|}
\hline & $\begin{array}{c}\text { Aşı olan } \\
(n=66)\end{array}$ & $\begin{array}{c}\text { Assı olmayan } \\
(n=571)\end{array}$ & $\begin{array}{l}\text { Toplam } \\
(n=637)\end{array}$ & $\mathbf{P}$ \\
\hline Erkek & 30 & 214 & 244 & 0,21 \\
\hline Kadın & 36 & 357 & 393 & 0,03 \\
\hline Doktor & $33(\% 13.75)$ & 207 & 240 & \\
\hline Diğer sağlık personeli & 33 & 364 & 397 & \\
\hline Hemşire & $11(\% 6.1)$ & 169 & 180 & \\
\hline Yardımcı sağlık personeli & 7 (\%8.9) & 72 & 79 & \\
\hline Diğer & $15(\% 10.8)$ & 123 & 138 & \\
\hline \multicolumn{5}{|l|}{ Yaş } \\
\hline$<29$ & 23 & 193 & 216 & 0,86 \\
\hline$\geq 30$ & 43 & 378 & 421 & \\
\hline $18-29$ & 23 & 193 & 216 & 0,557 \\
\hline $30-39$ & 17 & 186 & 203 & \\
\hline $40-49$ & 17 & 139 & 156 & \\
\hline$>50$ & 9 & 53 & 62 & \\
\hline \multicolumn{5}{|l|}{ Mesleki süre } \\
\hline$<10$ & 43 & 325 & 368 & 0,2 \\
\hline$\geq 11$ & 23 & 246 & 269 & \\
\hline $0-10$ & 43 & 325 & 368 & 0,063 \\
\hline $11-20$ & 9 & 142 & 151 & \\
\hline $21-30$ & 9 & 81 & 90 & \\
\hline$>31$ & 5 & 23 & 28 & \\
\hline \multicolumn{5}{|l|}{ Kronik hastalık } \\
\hline Yok & 55 & 491 & 546 & 0,55 \\
\hline Var & 11 & 80 & 91 & \\
\hline DM & 4 & 7 & 11 & \\
\hline $\mathrm{KAH}$ & 0 & 1 & 1 & \\
\hline КОАН & 1 & 1 & 2 & \\
\hline Diğer & 6 & 71 & 77 & \\
\hline Daha önce aşı olan & $61(\% 21)$ & 221 & 282 & 0,000 \\
\hline Olmayan & $5(\% 1)$ & 350 & 355 & \\
\hline
\end{tabular}

*DM: Diabetes Mellitus, KAH: Koroner Arter Hastalığı, KOAH: Kronik Obstruktif Akciğer Hastalığı

görülmüştür. Yaş grupları ve mesleklerine göre dağılımlar sırasıyla Şekil 1 ve 2'de verilmektedir. Mesleki deneyimleri 11,35 $( \pm 9,6)$ yıl olan katılımcıların \% 85,7 ( $\mathrm{n}=546)$ 'sinde herhangi bir kronik hastalık bulunmamaktadır. Kronik hastalığı olan grupta en sık diabetes mellitus (\% 14) görülmektedir. Bütün katılımcılar grip olduğunda bakım verdiği hastalara bulaşabileceğini bilmektedir. 
A. Haykır Solay ve ark., Üçüncü Basamak Sağlık Hizmeti Veren Bir Merkezde Sağlık Çalışanlarının İnfluenza Aşısına Yaklaşımı, Aşılama Oranları ve Nozokomiyal İnfluenza Sıklığı

Tablo 2. Aşı reddi nedenleri ve önceki yıllarda aşı olduğu halde bu yıl aşı olmayanların ret nedenlerinin karşılaştırılması.

\begin{tabular}{|c|c|c|c|c|c|}
\hline & \multicolumn{2}{|c|}{ Grup $1(n=350)$} & \multicolumn{2}{|c|}{ Grup 2 (n=221) } & \multirow[b]{2}{*}{$\mathbf{p}$} \\
\hline & $\mathbf{n}$ & $\%$ & $\mathbf{n}$ & $\%$ & \\
\hline Kendisine grip virüsünün bulaşmayacağını düşünme & 83 & 23,4 & 33 & 15,3 & 0,020 \\
\hline Aşı olunca grip olduğunu düşünme & 25 & 7,0 & 58 & 26,9 & $<0,001$ \\
\hline Aşının koruyuculuğuna inanmama & 121 & 34,1 & 59 & 27,3 & 0,091 \\
\hline Aşının yan etkilerinden korkma & 68 & 19,2 & 35 & 16,2 & 0,374 \\
\hline Enjeksiyondan korkma & 22 & 6,2 & 7 & 3,2 & 0,119 \\
\hline Aşı üreticilerine güvenmeme & 34 & 9,6 & 17 & 7,9 & 0,488 \\
\hline Kendisine hiç anlatılmaması & 34 & 9,6 & 19 & 8,8 & 0,755 \\
\hline Sağ|ıklı bireylere gerekli olmadığını düşünme & 69 & 19,4 & 33 & 15,3 & 0,208 \\
\hline Zaman bulamama & 13 & 3,7 & 25 & 11,6 & $<0,001$ \\
\hline
\end{tabular}

* Grup 1: Hayatı boyunca hiç influenza aşısı olmamış olanlar.

*Grup 2: Daha önceki sezonlarda aşı olduğu halde 2018-19 sezonunda aşılanmamış olanlar

*Her katılımcı, kendisinin aşıyı reddetmesine neden olan birden fazla nedeni işaretleyebildi.

Hastanemizde, 2018-2019 influenza sezonunda, tüm çalışanların \% 12,2'sine ( $n=250)$, ankete katılanların \% 10,4'üne ( $n=66$ ) influenza aşısı yapıldığı görülmektedir. Ankete katılan grupta doktorların \% 13,8 (33/240)'lik aşılanma oranı ile uyumu en yüksek grup olduğu görülmektedir. Doktor dışı sağlık çalışanının aşılanması ile aralarında istatistiksel olarak anlamlı fark bulunmaktadır $(p=0,03)$. Aşı olan 66 çalışandan 43 (\% 68,2)'ü mesleğinin ilk 10 yılı içerisinde olup bu fark yüksek olsa da aşılanmayı reddeden grupla birlikte değerlendirildiğinde istatistiksel olarak anlamlı bulunmamaktadır $(p=0,02)$ (Tablo 1).

Katılımcıların 282 (\% 44,1)'si daha önceki yıllarda aşı olduğunu, fakat bunlardan sadece 61 (\% 21)'i bu yıl da aşılandığını belirtmektedir.

Aşı ret nedenleri arasında aşının koruduğuna inanmama birinci sırada (\% 28,6) yer almaktadır. Önceki sezonlarda aşı oldu halde 2018-19 sezonunda aşılanmayanlarda ise aşının koruduğuna inanmama $(\% 27,3)$ ve aşı olduğunda grip olduğunu düşünme $(\% 26,9)$ en sık aşılanmama nedenleri arasındadır. Gruplar karşılaştırıldığında grup 2'de aşı olduğunda grip olduğuna inanma ve zaman bulamama gerekçeleri istatistiksel anlamlı olarak yüksek bulunmuştur ( $p<0,001$ ) (Tablo 2 ).

Sağlık çalışanlarının 2018-2019 influenza dönemi öncesi aşılanma oranlarının düşük olduğunun görülmesi üzerine, aynı sezonda hastanemizde görülen Ni olgularının tespit edilmesi amaçlanmıştır. Hastanemizde yatan ve influenza benzeri hastalık tanısı ile nazofaringeal sürüntü alınan 59 hastanın dosyası incelenmiştir. Bunlardan 40' toplum kökenli influenza, 19'u (\% 32,2) ise Ni olduğu görülmüştür. Ni tanısı konulan bu 19 hastanın 14'ünün erkek, yaş ortalamalarının ise 53,3 olduğu görülmektedir. Yalnızca üçünde etken PCR ile izole edilmiştir (H3N2; $n=2, H 1 N 1 ; n=1)$. On dokuz hastanın dokuzunda pnömoni geliştiği görülmüştür. Bu dokuz hastanın üçü $(\% 15,7)$ ALL, akciğer kanseri ve kronik böbrek yetmezliği tanıları ile takip edilmekteyken influenza pnömonisi sonrası kaybedilmiştir.

\section{TARTIŞMA}

Sağlığın korunabilmesi ve bulaşıcı hastalıkların yayılımının önlenmesi konusunda yürütülen en önemli halk sağlığı uygulamalarından biri aşı çalışmalarıdır. Influenza tüm dünyada morbidite, mortalite ve iş gücü kaybına neden olmaktadır. Hastane kaynaklı olan salgınlarda mortalite oranı artmaktadır. Sağlık çalışanları asemptomatik olsa da virusu hastalara bulaştırabildiği için her yıl influenza aşısı uygulanması önerilmektedir. Sağlık çalışanlarının aşılanması, onları influenza enfeksiyonuna karşı koruyarak iş gücü kaybını önlediği gibi virusun hastalara ve diğer sağlık çalışanlarına bulaşarak 
hastalık yükünün artmasının önüne geçilmesini sağlamaktadır(10). Fakat tüm dünyada hedeflenen aşılama düzeyine ulaşma konusunda sıkıntılar yaşanmaktadır. Ülkemizde yapılan çalışmalarda sağlık çalışanlarının aşılanma oranı \% 4,3-18,4 arasında bildirilmektedir ${ }^{(18,20,22)}$. Bu oran iki çalışmada daha yüksektir (\% 30,6-34,6 $)^{(9,24)}$. Pandemi döneminde ise aşılanma oranının yükseldiği (\% 30,4-56,4) görülmektedir(1,4,11,17,23). Bizim çalışmamızda da ülkemiz verilerine benzer olarak, \% 10,4 aşılama oranına ulaşılabildiği görülmektedir.

Diğer ülkelerde de hedeflenen aşı oranlarına ulaşılamadığı bildirilmekle beraber ülkemize benzer sonuçların yanı sıra \% 90 aşılama oranlarına ulaşııdığı bildirilen bölgeler de bulunmaktadır. Yunanistan'da sağlık çalışanlarının aşılanma oranları ülkemizdeki sonuçlarla benzerdir. Maltezouve ve ark.'nın ${ }^{(15)}$ çalışmasında sağlık bakanlığı tarafından oluşturulan aşı yönlendirme komitesinin çalışması ile aşılanma oranının \% 10,9'dan \% 24,9'a çıktığı bildirilmektedir $^{(15)}$. Portekiz'de ise pandemi döneminde ulaşılabilen aşılama oranı \% 38 civarında bildirilmektedir ${ }^{(5)}$. Almanya'dan bildirilen bir çalışmada bu oran $\% 40,5^{\prime} \operatorname{tir}^{(3)}$. İtalya'da yapılan çalışmada sağıık çalışanlarına uzman doktor tarafından verilen, standardize edilmiş bir eğitimle \% 31 olan aşılanma oranı ancak \% 42'ye çıkarılabildiği bildirilmektedir( ${ }^{(6)}$. Japonya'da pandemi döneminde sağlık çalışanlarının \% 84,7 oranında aşılandığı bildirilmektedir ${ }^{(13)}$. Amerika'da sağlık çalışanlarının influenza aşısı olma oranı ortalama olarak \% 40 iken zorunlu hale getirilerek oranın \% 98'e çıkması sağlandığı, böylelikle salgınların daha kolay kontrol altına alınabildiği bildirilmektedir. Bu nedenle Helena ve ark. ${ }^{(16)}$ derlemesinde morbidite ve mortalitesi yüksek olan aşı ile önlenebilir hastalıklarda aşılamanın zorunlu olması gerektiğini savunmaktadır. Deni ve ark. ${ }^{(7)}$ da derlemelerinde eğitimin önemini vurgulamakla beraber yüksek riskli gruba hizmet veren çalışanların zorunlu aşılanmaları gerektiği üzerinde durmaktadırlar. Ülkemizde influenza aşısı tüm risk grupları için önerilmektedir; zorunlu değildir. Bu nedenle, sağlık çalışanlarının aşılanmasında pandemi dönemlerinde dahi hedeflenen düzeye ulaşılamamaktadır ${ }^{(11)}$.

Meslek gruplarına göre değerlendirildiğinde doktorların aşılanma oranı sıklıkla hemşirelerden ve yardımcı sağlık personelinden yüksek bulunduğu bildirilmektedir ${ }^{(1,4,11,22,24)}$. Daha az sayıda çalışmada ise doktorlarla yardımcı sağlık personeli arasında aşılanma oranları arasında fark bulunmamaktadır ${ }^{(9,19)}$. Bizim çalışmamızda da doktorlarda aşılanma oranı diğer sağlık çalışanlarından yüksek bulunmuştur.

Anket çalışmalarında belirtildiği üzere sağlık çalışanlarının influenza aşısı olmama nedenleri arasında aşının gerekliliğine inanmama, aşı olduğunda grip olduğunu düşünme, yan etkilerinden korkma, aşının koruyuculuğuna inanmama, zaman ayıramama en sık nedenler olarak belirtilmektedir(9,17,22). Bizim çalışmamızda da en sık neden olarak aşının koruyuculuğuna inanmama, kendisine grip virüsünün bulaşmayacağını düşünme, aşının yan etkilerinden korkma, sağ ıklı bireylere gerekli olmadığını düşünme gibi nedenlerle aşı yaptırılmadığı görülmektedir.

Sağlık çalışanlarının solunum yolu patojenleri ile karşılaşma ihtimali yüksektir. Hastalık riski sadece kendileri için değil tüm bakım verdikleri hastalar için de yüksektir. Bu nedenle sağlık çalışanlarının influenza aşısı olma oranları Ni sıklığını etkiler ${ }^{(7)}$. Ni sıklığı 2011 ve 2013 yıllarında yayımlanan çalışmalarda \%2-4,3 bildirilmektedir(14). Huzly ve ark.'nın ${ }^{(12)} 2014$ yılında yayımladığı çalışmasında bu oran \% 20'dir. Eibah ve ark.'nın ${ }^{(8)}$ yaptığı çalışmada Ni tanımı moleküler bazlı tiplendirme yöntemi ile konulmuş olup oran \% 24 bulunmuştur. Bizim çalışmamızda Ni tanısı klinik olarak konuldu ve olgularının oranı \% 32,2 ile literatürden yüksek olarak bulunmuştur.

$\mathrm{Ni}$ olguları toplum kökenli olanlardan farklılık gösterir. Yaş ortalamaları daha yüksektir ve malignite, immunsüpresyon, solid organ alıcısı olmak gibi komorbit hastalıkları vardır. Ölüm oranı \% 9 olarak 
A. Haykır Solay ve ark., Üçüncü Basamak Sağlık Hizmeti Veren Bir Merkezde Sağlık Çalışanlarının İnfluenza Aşısına Yaklaşımı, Aşılama Oranları ve Nozokomiyal İnfluenza Sıklığı

bildirilmektedir(12). Bizim çalışmamızda da $\mathrm{Ni}$ olgularında yaş ortalaması daha yüksekti ve hepsinde komorbit hastalık vardı. Mortalite oranı ise \% 15,7 idi. Sağlık çalışanlarının aşılanması ile hastalık yükü azaltılabilir ve böylelikle komorbiditesi olan bu hastalarda mortalite için yeni risk faktörü eklenmesinin önüne geçilebilir.

Tüm dünyada olduğu gibi ülkemizde de aşı karşıtlarının sayısı artmaktadır. Ülkemizde zorunlu olarak yapılan çocukluk çağı aşılarına dahi 2010 yılından sonra retler başlamış olup bu oran giderek artmaktadır. Aşı karşıtları tarafından aşı içerisinde bulunan maddelerin otizm gibi hastalıklara neden olduğu, aşı firmalarının güvenilir olmadığı; ticari kaygılarınön planda olduğu söylenerekspekülasyonlar yapılmaktadır ${ }^{(2)}$. Bir çok platformda söz sahibi olan bu insanlar -sağlık çalışanları dahil- tüm toplumu etkilemektedir. Aşılanmayla ilgili yapılan hizmet içi eğitimlere katılım az olduğu gibi birebir yapılan eğitimlerle de aşılama oranının istenilen düzeye getirilemediği ve hatta bakış açısının dahi değiştirilemediği görülmektedir. Bu nedenlerle kritik hasta bakımında görevli olan çalışanların aşılanmasının zorunlu hale getirilmelidir. Böylelikle; kritik hastaların mortalite için ilave bir risk faktörü ortadan kaldırılabilir. Ayrıca, aşı eğitimi için daha etkin yöntemler bulunmalı, medya gibi popüler olan daha etkin araçlar da kullanılmalıdır. İstenilen aşılama oranlarına ulaşılamadığında ise tüm sağlık çalışanlarının zorunlu aşılanması konusunda değerlendirmeler yapılmalıdır.

Etik Kurul Onayı: S.B.Ü. Dışkapı Yıldırım Beyazıt Eğitim Araştırma Hastanesi Etik Kurulu'nun onayı alınmıştır (12.11.2018/56-08).

Çıkar Çatışması: Yazarlar tarafından herhangi bir çıkar çatışması bildirilmemiştir.

Ethics Committee Approval: S.B.Ü. The approval of Dışkapı Yıldırım Beyazıt Training and Research Hospital Ethics Committee was obtained (12.11.2018 / 56-08). Conflict of Interest: No conflict of interest has been reported by the authors.

\section{KAYNAKLAR}

1. Arda B, Durusoy R, Yamazhan T, et al. Did the pandemic have an impact on influenza vaccination attitude? A survey among health care workers. BMC Infect Dis. 2011;11(1):87. https://doi.org/10.1186/1471-2334-11-87

2. Bozkurt HB. Aşı Reddine genel bir bakış ve literatürün gözden geçirilmesi. Kafkas Tıp Bilimleri Derg. 2018;8(1):71-6.

3. Brandt C, Rabenau HF, Wicker S. Attitudes of influenza-vaccinated health care workers toward masks to prevent nosocomial transmission of influenza. Influenza and other respiratory viruses. 2011;5(1):61-6.

https://doi .org/10.1111/j.17502659.2010.00174.x

4. Budak S, Acar A, Karacaer Z, et al. GATA Haydarpaşa Eğitim Hastanesi'ndeki sağlık çalışanlarının pandemik influenza A/H1N1 aşılaması ve aşıya bağlı yan etkiler. Turk Hij ve Den Biyol Derg. 2011;68(4):185.

5. Costa JT, Silva R, Tavares M, Nienhaus A. High effectiveness of pandemic influenza $A$ (H1N1) vaccination in healthcare workers from a Portuguese hospital. Int Arch Occup Environ Health. 2012;85(7):747-52. https://doi.org/10.1007/s00420-011-0714-8

6. Costantino C, Restivo V, Gaglio V, et al. Effectiveness of an educational intervention on seasonal influenza vaccination campaign adherence among healthcare workers of the Palermo University Hospital, Italy. Ann Ig. 2019;31(1):35-44.

7. Dini G, Toletone A, Sticchi L, Orsi A, Bragazzi NL, Durando $P$. Influenza vaccination in healthcare workers: a comprehensive critical appraisal of the literature. Hum Vaccin Immunother. 2018;14(3):772-89.

https://doi.org/10.1080/21645515.2017.1348 442

8. Eibach D, Casalegno JS, Bouscambert $\mathrm{M}$, et al. Routes of transmission during a nosocomial influenza A (H3N2) outbreak among geriatric patients and healthcare workers. J Hosp Infect. 
2014;86(3):188-93.

https://doi.org/10.1016/j.jhin.2013.11.009

9. Erbay AK, Baştuğ A, Aktaş D, et al. Ankara Numune Eğitim ve Araştırma Hastanesi'nde sağıık çalışanlarının influenza aşısına karşı tutum ve davranışlarının değerlendirilmesi. Flora. 2007;12(3):141-7.

10. Grohskopf LA, Sokolow LZ, Broder KR, et al. Prevention and control of seasonal influenza with vaccines: recommendations of the Advisory Committee on Immunization PracticesUnited States, 2018-19 influenza season. MMWR Recomm Rep. 2018;67(3):1. https://doi.org/10.15585/mmwr.rr6703a1

11. Gürbüz $Y$, Tütüncü $E E$, Şencan $I$, ve ark. İnfluenza A (H1N1) 2009 pandemisinde hastane çalışanlarının grip aşısına yaklaşımlarının araştırılması. Pamukkale Tıp Derg. 2013;6:(1):12-7.

https://doi.org/10.5505/ptd.2013.07078

12. Huzly D, Kurz S, Ebner W, Dettenkofer M, Panning M. Characterisation of nosocomial and community-acquired influenza in a large university hospital during two consecutive influenza seasons. J Clin Virol. 2015;73:47-51. https://doi.org/10.1016/j.jcv.2015.10.016

13. Igari $\mathrm{H}$, Watanabe $\mathrm{A}$, Chiba $\mathrm{H}$, et al. Effectiveness and safety of pandemic influenza A (H1N1) 2009 vaccine in healthcare workers at a university hospital in Japan. Jpn J Infect Dis. 2011;64(3):177-82.

14. Macesic N, Kotsimbos TC, Kelly P, Cheng AC. Hospital-acquired influenza in an Australian sentinel surveillance system. Med J Aust. 2013;198(7):370-2. https://doi.org/10.5694/mja12.11687

15. Maltezou HC, Keterelos P, Protopappa K, Dounias $G$. Seasonal influenza vaccination in healthcare personnel in Greece: 3-year report. Future Microbiol. 2019;14(9s):55-8. https://doi.org/10.2217/fmb-2018-0266

16. Maltezou HC, Theodoridou K, Ledda C, Rapisarda $\mathrm{V}$, Theodoridou M. Vaccination of healthcare workers: is mandatory vaccination needed?
Expert Rev Vaccines. 2019;18(1):5-13.

https://doi.org/10.1080/14760584.2019.1552 141

17. Ormen B, Türker N, Vardar i. Hastane personeline pandemik influenza A (H1N1) aşı uygulamasının ardından aşılama hakkındaki görüşler ve ggzlenen yan etkiler. Mikrobiyol Bul. 2012;46(1):57-64.

18. Öncel $E K$, Büyükcam $A$, Cengiz $A B$, Kara $A$, Ceyhan $M$, Doğan BG. Hekim ve hemşire dışındaki hastane personelinin mevsimsel grip eşısı ile ilgili bazı bilgilerinin, görüşlerinin ve tutumlarının değerlendirilmesi. J Pediatr Inf. 2015;9(2):68-75.

https://doi.org/10.5152/ced.2015.2009

19. Özkaya Parlakay A, Abdulmumin A, Kara A. Pandemik influenza salgını öncesinde sağlık personelinin pandemik grip aşısı ile ilgili görüşleri. J Pediatr Inf. 2012;6(2):37-9.

20. Polat $H H$, Yalçin $A N$, Öncel S. Influenza vaccination; Rates, knowledge and the attitudes of physicians in a university hospital. Turkiye Klin J Med Sci. 2010;30(1):48-53. https://doi.org/10.5336/medsci.2008-8117.

21. Prevention Strategies for Seasonal Influenza in Healthcare Settings. Centers for Disease Control and Prevention.

https://www.cdc.gov/flu/professionals/ infectioncontrol/healthcaresettings.htm. (Erişim tarihi: 22.08.2019).

22. Sarı T, Temoçin F, Köse H. Sağlık çalışanlarının influenza aşısına yaklaşımları. Klimik Derg. 2017;30(2):59-63. https://doi.org/10.5152/kd.2017.15

23. Sevencan F, Ertem M, Özçullu N, Dorman V, Kubat NK. The evaluation of the opinions and attitudes of healthcare personnel of the province Diyarbakir against influenza A (H1N1) and the vaccination. Hum Vaccin. 2011;7(9):94551.

https://doi.org/10.4161/hv.7.9.16368

24. Ulusoy $E$, Arıkan D. Çocuk ünitesinde çalışan sağlık bakım personelinin grip aşısı oranları. Turkiye Klinikleri J Nurs Sci. 2010;2:11-5. 